want, as much as anybody, to-if I may use a vulgarism again-" "get on with it." I do not say that the past times were better than these, but I believe that if we want to avoid the past our only way of avoiding something worse is to use the past and all its teaching for the purpose of new endeavours. I am sceptical of tendencies that dissociate themselves from known physiological principles, and therefore I am sceptical of remedies that are thrust upon us from outside, the result of illdigested hypotheses, ar: which have never been submitted to proper control. Equally am I sceptical of remedies which, though they arise inside, are hurried into the therapeutic field by enthusiasts and jealously guarded against healthy criticism.

No doubt our fathers in the therapsutic field thought too much and tried too little. I am not sure that we, in our turn, have not reversed the error. We have been deluged with new facts and we clamour for still more. Though we are already dyspeptic, we want more food to bolt. We suffer from a sort of mental achylia. There seems no time to chew; and thought, which is the juice by which facts may be prepared for assimilation, has become démodé. Our textbooks are "synopses," our scientific meetings serve very largely only to catalogue more and more conclusions of disconnected researches. A table of figures or even a mathematical formula gives us the comfortable feeling that we are at last arriving at exactness and precision. But to produce these things is the function of the instrument and the machine rather than of the mind. They are merely the pabulum for the mind ; they are not the product of the mind's synthetic, or even its analytic, faculty.

\section{Pacings To and Fro}

I believe whole-heartedly in research. "Seek out Nature by observation and experiment," said the great founder of scientific medicine. But Harvey's real greatness lay not in the discovery of new facts, but in the power of his mind to dissociate and to assimilate, and thus to construct new ideas. The labours in his laboratory were essential, but those frequent pacings to and fro under the trees at Coombe were vital. I sometimes wonder if it would help us to c'ose down the laboratories for a while, to hand over the wards to our juniors, and to get together and to try to see where we are. Perhaps we could then marshal our facts-clinical, immunological, and morbid anatomical-see where the gaps are, and begin to make more concerted efforts to fill them. Having done this we might try to dissociate and combine them by deliberation and some constructive thought.

The truth is, although science never offered us so many new facts before or so many new instruments for possible exploitation in therapeutics, we seem for the time being less capable than we were of making use of them, except, as I have sa:d, by way of direct action. But the proper adaptation of scientific discovery to therapeutics requires the careful application of physiological principles and a knowledge of the deviations from the physiological that constitute disease. This invo'ves indirect action, which does not fit with the spirit of the times. Just as nations have become intolerant of the past, have revolted against the lag which tradition and convention seemed to be putting upon human progress, and have decided to attack their troubles by some direct and dramatic movement, so in the struggle with disease we are exhibiting a like intolerance with the slower methods of past generations, and many of us have decided upon direct action. In both cases the decision leads to a great adventure which, if it succeeds in establishing harmony for the time being, must still and inevitably be followed by a return to principles from which there is no permanent escape. But if the adventure fails it spells a worse disease, or death, to the body politic and to the patient alike.

There is a story told concerning the men who first conceived and drew up the constitution and working plan of the Soviet State. Whilst in doubt about the practicability of their scheme it was suggested to them that they should inquire of a certain wise old rabbi if the thing were feasible. Accordingly, they presented themselves at the cave of the recluse and, showing and explaining the scheme, they asked if it could be accompished in Russia. The old man reserved judgement and bade them come again next day. They returned in due course, and the rabbi said to them: "Yes, this thing can be done in Russia . . . but no one will live there." There are things that can be done in therapeutics which may not be worth doing. I trust I do not offend anyone by my topical references. I say what I believe, and the references seem apposite to my theme. The mass-man, in his effort to heal the troubles of the world, has become primitive. That he is Bolshevist or Fascist or Nazi is not the thing that matters. What matters is that he has cut himself adrift-from culture-a fatal detachment. I think that we are seeing an analogous movement in therapeutics-its invasion by primitives, bent on seeing what can be done by direct action severed from physiological principles. To which, inevitably, we shall some day return; I trust at not too distant a date.

\section{SOME MEDICAL ASPECTS OF BOARDING. SCHOOL LIFE *}

\section{By}

REGINALD MILLER, M.D., F.R.C.P.

SENIOR PHYSICIAN, PADDINGTON GREEN CHILDREN'S HOSPITAL ; PHYSICIAN, ST. MARY'S HOSPITAL, LONDON

Childrèn of well-to-do parents may spend ten or more most important years at our private or public boarding schools, and often for the best results there is need for co-operation between the school authorities and the doctor. Yet members of the scholastic and medical professions seem seldom to meet to discuss matters of common interest. Perhaps this is because, as a general rule, school life of to-day goes smoothly, happily, and successfully. Certainly doctors need not, for the majority of children, regard the school years as a period of unavoidable strain and difficulty: rather they have every reason to anticipate nothing but benefit for their child patients. No one can admire more than I the charming and sensible type of child that our preparatory schools turn out to-day.

Yet there must always be a certain number of children who will fit into school life only with considerable difficulty. In them there is a possibility of success and a possibility of failure. They may not, perhaps, be very numerous; but their importance lies in the fact that they are the children who need the benefit of boarding-school life most. Such children are of various types. In some the difficulty lies in physical ill-health or delicacy, and in some the sensitive nervous system feels unduly the strain of school life. In others fears and shyness cause them to be so overlooked (as indeed they desire) that they do very little good at school. In another type difficulty arises from a devoted mother, whose stranglehold is such that neither the school nor the child has much chance to break away and make a success of things. Mention might be made of many other types of children who require, at least in their earlier terms, extra care on the part of the school and of the doctor. From a medical point of

* An address given at Broadstairs to a combined meeting of the medical and scholastic prolessions of Thanet, February, 1933. 
view these children form a great test of a school's efficiency: for if school is a success the child will make good ; if a failure the child will be harmed and further handicapped. There is nothing that can replace in its life the benefit of a satisfactory school career.

It is about the school life of these children that doctors are so often consulted, and I think that there are many matters, causing uneasiness to the minds of parents, of which more is heard by doctors than by the school authorities. I propose, therefore, to discuss some of the factors which seem to me to lead to lack of the fullest benefit from school life or even to actual ill success. I shall deal with them under the headings of school, home, and health.

\section{SCHOOL FACTOR}

Choice of School.-Failure to fit in successfully at school is not necessarily the fault of the school or of the child: often the wrong type of school has been chosen. Generally speaking, boarding school is less of a strain than day school, with its dual interests for the child. I am often amazed at the length of day to which parents will submit day-school children. After the child returns in the evening there is homework, more hated and harmful than any other part of the day's work, and much more strain than " prep." in class. Boarding school is essential for solitary children, children of widows, and delicate town children. It is impossible to exaggerate the benefit that may accrue to the latter from years spent in the wonderful air of our health resorts. The plan of a weekly boarder is unsatisfactory to the school and difficult for the child, although some happy children from sensible homes manage it quite well. Mixed day and boarding schools are apt to be hard on the boarders whose hours have to suit the day pupils. Co-education schools have not, as yet, had the advantage of being patronized by ordinary children of ordinary parents. The youngest children may go to kindergartens or pre-preparatory schools, but as a rule they go into the bottom classes of ordinary boarding schools, where they settle down with a pleasure begotten of pride. It is not unimportant where these little folk go, for the worst bullying, especially at girls' schools, is apt to occur in the lowest forms. A dominating little girl will lead all the others against some harmless child for no reason save that she wishes to show off her power. It is not necessarily wise to send a child to a particular school merely because its brothers or sisters have been there before. There is more in the selection of a school for an individual child than this plan allows. Boarding school offers a fuller life, with less strain and greater opportunity for development of character and improvement in health than any other type of school. In many instances it is a necessity to the child: no alternative is half so good.

Climate.-As many children are sent to boarding school primarily for their health it is only common sense to choose the best climate. Speaking as I am in Thanet, I need hardly emphasize this point.

\section{Extra Care for Delicate Children}

A school is not a convalescent home, still less is it a nursing home: nevertheless there are many children, needing boarding-school life supremely, who will require extra attention if they are to be made successes. In most instances of physical delicacy this is only required for the first term or so: for the rest of its school life the child is well and strong. Additional rest is one of the needs of most delicate and nervous children, as I shall mention later. Particular attention should be paid to weight. It ought not to be difficult to have a list of children who should be weighed every fortnight or month. In any case, to have children weighed only at the beginning and end of term is not enough. It is not fair to send a child home having lost $4 \mathrm{lb}$. and no one to have noticed the change until the end of term. Unless there is some special reason to the contrary, a child should not be told its weight, and should be weighed with its back to the scale.

Nervous children who are notoriously bad mixers must be protected from incidental " ragging" and bullying. What may be harmless or even good for the ordinary child may mean disaster for them. The same holds good in class ; the teacher must distinguish the lazy, careless child from the nervous, scatter-brained, and perhaps half-scared child, and must know which child will improve with correction and which will just wilt under it. Generally speaking, the nervous child will react only to encouragement. Some have a special horror of certain lessons, particularly of mathematics. This subject should be taught by a highly paid professional dunce: no mathematician has any idea of the difficulties which children have over the elements of the subject.

Considerable experience is necessary in handling some of these difficult children. How often a trifling incident will put a child at loggerheads with its teacher! Members of the teaching staffs of schools should not be above taking advice from the head of the school. I have many times known the head to be the only person who could understand and get round a child. To do this, to put a nervous little girl on her feet, and to get her to take her proper place in the school, and to do it without allowing the child to develop a devastating passion for herself, is a very clever thing for any mistress to accom plish. These "pashes" play havoc with the nerves 0 children, and must be prevented at all costs.

Feeding.-Delicate children may need extra feeding or some modification of the school diet. What is more commonly required, however, is that the school should provide a liberal ordinary diet and should see that the child eats it. In this matter the school has a great advantage over the home. Often, indeed, the mother of an inveterate non-eater has given up the struggle, and has deliberately left it to the school to get the child into better habits. There are many interesting medical problems in connexion with such cases, but there is no doubt that in many of them habit plays a large part. These children, therefore, sitting scattered among the others, must be carefully watched at meals ; in most cases the child forgets its difficulties and goes ahead well. And this leads me to speak of the importance of the fourth or evening meal. In my opinion, there has been of late years a great improvement in this matter. Older children are getting proper meat suppers, and the tea meal has been reduced. Something more strengthening and less fattening is required than a surfeit of bread, butter, and jam. Even in preparatory schools there will probably be a certain number of older and also delicate children who will do better with a proper fourth meal in the day. There is no truth in the idea that children cannot sleep well after a good plain meal at night. On the contrary, they sleep quite well, just as they can play games directly after a middle-day meal large enough to immobilize an adult for the afternoon. It is to be hoped that these times of financial stringency will not cause any falling away from the high standard of school dietaries.

\section{Modern Psychotherapy}

It is impossible to speak about difficult or nervous children without making some mention of modern psychology and the methods of treatment based upon it. This matter is increasingly exercising the minds of parents. Already it is claimed that all peculiarities of school children, whether in temperament or deportment, should 
be referred to the doctor for psychological investigation and treatment. The child guidance movement shows us this doctrine at work among the children and in the homes of the poor. It is clear that we are in for a phase of it in which extravagances will not be lacking, and it will be interesting to see what the scholastic profession will make of it in practice. The children of the poor are accustomed to all manner of outside interference in their education from the time they matriculate, as it were, at the ante-natal clinic. Children in high-class schools are in a different position, and these schools should, I think, oppose the substitution of the doctor for the teacher in minor matters psychological. I say this because the teacher's contact with the child is such that the responsibility of understanding its mind cannot be transferred to the doctor; and because there is a danger that, with a doctor's investigation into its behaviour, the child will develop a morbid interest in itself.

Sometimes, I think, schools make the same error as the modern psychologist of treating what is essentially trivial as of great importance. All children, for instance, go through phases of lying and stealing. Even in the case of the grossest faults it is seldom wise to ostracize a child, or to expose it to the tender mercies of schoolmates. Surely a head should stretch many points to be loyal to a child, even in grave misdemeanours. The controlling idea should not necessarily be that the child has let the school down: may it not be that the school has let the child down? Whatever, then, may be the value of modern psychological methods in really abnormal children, there is possible danger from their use in ordinary children holding their own with more or less success in high-class schools.

\section{HOME FACTOR}

In order to get the best from school life, particularly in the case of delicate or difficult children, co-operation between the school and the parents is desirable. The difficulties in the attainment of this ideal, though not strictly of a medical nature, are often made obvious to the doctor, and I propose to discuss some of them candidly.

The viewpoints of parents and of the head of a school or school house are not quite the same. In sending a child to school, especially to boarding school, parents are doing what is to them a very big thing-namely, handing over their child to someone else who will have great influence over it. To the parents the child is not only theirs, but also distinctly an individual child, and they wish it to have individual attention. The head of a school, however, although wishing to give individual attention to each child, knows that there is another side to the questionnamely, that the school as a whole must run satisfactorily. He is, as it were, painting a picture, and if the design is a success the children-and for that matter the teaching staff-cannot do better than fit into it. It is surely in influencing a child for good by creating the right atmosphere that the art and genius of keeping school lies. Parents are disposed to be impatient or jealous of this side of a schoolmaster's work; they are all for individual attention, and in this they are apt to be unreasonable. If parents thought the matter out they would realize that it is the tone of the school which is so important for the child. In the right atmosphere the child comes uncler a discipline which works silently and automatically, with the result that it falls into line with a minimum of dragooning and pressure. Such an atmosphere spells freedom for the child, and at the same time helps it to choose to behave reasonably and unselfishly.
To turn to quite a different matter, could not cooperation between the parents and the school be promoted by the issue of school reports in a form which has something more than hoary antiquity to commend it? Only too often reports seem to be written on the principle of " the least said the soonest mended." I would urge that the head's report, which is the important one, especially in preparatory boarding schools, should be something fuller than a line at the bottom of a sheet of paper, and more illuminating than the usual non-committal " Has done well, but could do better." I suggest that this report should be written separately from the rest, so that the child does not necessarily see it. It should be full enough to mention the child's successes as well as its difficulties and failures, and, though not couched in terms of advice, should perhaps be some guidance to parents. Again, might not more use be made of halfterm reports? Lastly, might it not sometimes be advantageous if parents were expected to report to the school concerning the holidays, and for the child to be aware that such a report would be sent? This plan is often of help in dealing with children who behave well at school and outrageously at home, and tends towards co-operation between the school and the parents.

Should the parents seriously distrust the school the child is better moved elsewhere ; but how many problems might be solved if parents could or would tell their difficulties to the school! In their relation to parents the schoolmaster and the children's physician have much in common. They may merely tolerate the parents or may make an effort to influence them and win them to their views. The heads of schools have a reputation for being somewhat intolerant towards parents. How far this is so I should not like to say: but I think it is certainly true that parents are much more shy of head masters and mistresses than they are of their children's physicians.

\section{- Health Factor: Fatigue}

The relation of the physical health of children to their mental reactions to education and school life is a subject of great importance. I can, however, only deal with one aspect of it here-namely, fatigue in children. I have chosen this because I think it is the commonest, and perhaps the least appreciated, of the causes of transient or even permanent ill success at school. The really psychopathic child is outside my scope, for I want to discuss briefly the causes and effects of fatigue in the more or less ordinary children who are adapting themselves to the life of private and public schools with varying degrees of strain and success. Generally speaking physical fatigue, although obvious to the trained eye in the child's face and carriage, shows itself chiefly in nervous and mental symptoms. The type of symptom depends upon the type of child. The question may be asked if it is possible to over-fatigue a normal, wellbalanced child. I should be inclined to say that, if the child is left to itself, this is not possible: it would automatically sleep off its physical fatigue, and, by changing its occupation, relieve its mental fatigue. Unfortunately, as so often happens, the child is not left to itself. Its lack of attention, inaccuracy, and stupidity are carefully noted, and it is spurred to greater efforts, which can only be made at the risk of added fatigue. The highly strung nervous child has less reserve and so fatigues more easily than the more normal child, and its symptoms are different. Instead of becoming dull and apparently lazy, it becomes restless, emotional, irritable, scatter-brained, wildly disobedient, and negative. Such a child, with its bullying, selfish ways, may be the cause of an extraordinary amount of unhappiness in others. When to such symptoms as these are added refusal of food and 
loss of sleep, a picture of severe fatigue is presented. The point that I want to make here is that the child will hardly ever complain of fatigue; this will be apparent in alterations in application and in behaviour. In other words, the first to have the opportunity of recognizing the onset of fatigue in a child will be the school teacher, and from this responsibility there is no escape.

The causes of fatigue may be in the child or in the school regime. Age is significant. I should say that children in pre-preparatory and preparatory schools are most prone to show fatigue by unsatisfactory behaviour and progress, although in girls fatigue may mar educational effort throughout school life. In boys, after a year or two at a public school, fatigue seems to lead more to illness than to nervous symptoms; by this time the boy has learnt to fend for himself and, be they masters or school-fellows, to persecute those who persecute him. Rapid growth in height is another strain on the child, and gives rise, also, I think, to diminished resistance to infections.

The liability to scrious fatigue is greatly increased by any sort of subnormal physical health. Although it is not true to say that a child who is kept in good physical health will be free of physical and mental fatigue, yet there is an element of truth in the statement. Certainly the physical health of any child showing persistent symptoms of fatigue needs careful investigation. Some form of chronic toxaemia-often of obscure origin-may be at work, as, for example, disease of the tonsils or antra, disease of the bronchial glands, or, what is perhaps still more frequently found, toxaemia arising from the intestine, the condition which, in my view, is often falsely called " acidosis." Activity of the endocrine glands may also cause fatigue. Severe cases of fatigue are seen in adolescent girls, particularly just now in connexion with the prevailing habit of slimming. Many apparently alarming disorders of behaviour and thought at this age may mean nothing unduly serious.

The causes of fatigue attributable to school regime are numerous. I have already mentioned the choice of school and climate, and have discussed the question of diet and the great importance of ensuring that the child takes a proper quantity of food. The amount of rest provided is of the utmost importance. The hours devoted to sleep are mainly adequate, except, perhaps, in the upper forms at public schools. Rest, however, is not merely a matter of sleep. Nothing tries the nerves of some children more than the perpetual noise and rowing that may go on. Some period of silent rest, such as lying down with a book, should be ordered daily, and is often popular. Meals, too, should be taken in comparative quiet. It must be mentioned that summer-time means curtailed sleep for many children.

In my opinion the hours of work are far too long, and the harm that these long hours might do is only avoided by the slow pace which is set. The clever child learns to work slowly, and so spares itself, but the nervous child must work at high pressure, and thus may come badly to grief. Praiseworthy efforts are made in some schools to separate the quicker workers from the slower cnes. From what I have heard, the Dalton system seems to make an effort to teach a child how to tackle its nork and to take its own time over it. Some of our public schools for boys still lay themselves open to criticism concerning the activity they exact from the boys before breakfast.

Lastly, there is the difficult question of fatigue from examinations. When examinations are taken by children in their stride, as it were, they are harmless and useful ; but public examinations, which have become competitive, are apt to be tests of a good memory and a smart coach.
Such examinations certainly put an immense strain on some children.

As regards the treatment of these tired children, the first essential is that the tired ones should be recognized, and I have already emphasized upon whom the responsibility for this must necessarily fall. The teacher must bo able to distinguish between the actual fatigue and natural laziness, wilfulness, incompetence, or the results of fear. If in doubt the effect of a day or two in bed should be tried. Fatigue should be the first thing to occur to the mind to account for deterioration in work or character, and the doctor should be consulted on the possibility of a physical cause. For the rest it should be possible, especially in preparatory schools, to give the child an occasional day in bed, to provide extra rests and perhaps extra food, and to allow breakfast in bed ; the latter does not seriously interfere with education, and it materially diminishes fatigue. It must always be remembered that a child has a natural tendency to right itself. I am sure that drastic alterations in its life, and evidence of concsin in its psychology, should be avoided, and that the happiest results will be obtained by minor modifications of the school regime, friendly explanations, and sympathetic encouragement, all carried out quietly and with. the lightest of touches.

\section{MODERN VIEWS ON THE MECHANISM OF GALLSTONE FORMATION}

BY

DAVID H. PATEY, M.S., F.R.C.S.

STREATFIELD RESEARCH SCHOLAR OF THE ROYAL COLLEGE OF PHYSICIANS OF LONDON AND THE ROYAL COLLEGE OF SURGEONS OF ENGLAND

Gall-stones are a common cause of pain and disability, and therefore a considerable amount of work has been done to determine the causes of their formation and the best methods of treatment. The subject has been investigated from various angles-clinical, morbid anatomical, bacteriological, biochemical, and experimenta!-and much of the work is scattered about in various types of journal and not readily available to the general reacier. A brief review of modern views on gall-stone formation may therefore be of interest.

\section{The Factor OF Infection}

The first difficulty that arises is the definition of " modern," and how new a view has to be for inclusion in that term. In this article an attempt will be made to get over that difficulty by first of all giving Naunyn's classical theory of gall-stone formation, and then discussing in what ways our views have had to be modified as a result of increasing knowledge. Although this theory dates from the last century, it was widely accepted in its entirety as the best explanation of the formation of gall-stones until a comparatively few years ago. According to Naunyn, the essential factor in the formation of all gall-stones was infection, the usual infecting organisms being of intestinal origin. These organisms acted on the wall of the gallbladder and gave rise to a " lithogenous catarrh," as a result of which cholesterol was formed by the gall-bladder wall and shed into the lumen of the gall-bladder, together with small quantities of calcium and organic matter. If in sufficient concentration, these substances in the presence of stasis combined with the pigments of the bile to form a calculus. As a result of secondary cholesterolization of a primary mixed calculus, it was postulated that eventually a pure cholesterol calculus might be produced. Naunyn appreciated that gall-stones were commoner in 